ISSUES IN PUBLIC HEALTH

\title{
The universities of Stellenbosch/Cape Town low- carbohydrate diet review: Mistake or mischief?
}

\author{
Z Harcombe, ${ }^{1} \mathrm{PhD}$; T Noakes, ${ }^{2} \mathrm{OMS}, \mathrm{MB} \mathrm{ChB}, \mathrm{MD}, \mathrm{DSc}, \mathrm{PhD}(h c)$ \\ ${ }^{1}$ Public Health Nutrition, Cardiff, UK \\ ${ }^{2}$ Department of Human Biology, Faculty of Health Sciences, University of Cape Town, South Africa
}

Corresponding author: T Noakes (noakes@iafrica.com)

\begin{abstract}
A 2014 meta-analysis from the universities of Stellenbosch and Cape Town reported that diets with a lower-carbohydrate (CHO) content are no more effective for producing weight loss than are high-CHO diets, so-called isoenergetic 'balanced' diets. We have re-examined the article and found numerous errors, many material in nature. Studies were included that failed the authors' own inclusion criteria; invalid and subjective meta-analysis sub-grouping was used; and data extraction was repeatedly inaccurate. All but one error favoured the balanced diet. The article was widely publicised, highly impactful and inaccurate. This begs the question: mistake or mischief?
\end{abstract}

S Afr Med J 2016;106(12):1179-1182. DOI:10.7196/SAMJ.2016.v106i12.12072

In July 2014, the South African (SA) media reported that, by proving that low-carbohydrate $(\mathrm{CHO})$ diets were not better than 'balanced' eating, ${ }^{[1]}$ a recently published article $^{[2]}$ from the universities of Stellenbosch and Cape Town had effectively 'debunked the Banting diet. ${ }^{[3]}$ Other reports echoed this sentiment. The Cape Times personalised the message: 'Noakes's low-carb diet not healthier', while quoting the chief executive of the Heart and Stroke Foundation of SA: 'Based on the current evidence we cannot recommend a low carbohydrate diet to the public. ${ }^{[4]}$

The claim that a low-CHO diet was no better than balanced eating does not 'debunk' the low-CHO diet. These reports could as easily have stated that eating a balanced diet is no better for producing weight loss than eating a low-CHO diet is. This media positioning is interesting and particularly important in the current context that low-CHO diets have been placed on trial in SA. ${ }^{[5]}$

More objective reporting of Naude et al.'s ${ }^{[2]}$ systematic review should have made two important points:

First, the study could not provide any information about Banting or low-CHO diets because it failed to study either. The average carbohydrate intake for the 14 studies included in the systematic review $^{[6]}$ was $35 \%$ (fat $35 \%$; protein $30 \%$ ). ${ }^{[7-20]}$ This is substantially different from the $5 \% \mathrm{CHO}(<50 \mathrm{~g} /$ day $)$, moderate protein, and high fat, which is the dietary composition of the low-CHO diet promoted for the therapeutic management of obesity and type 2 diabetes mellitus. ${ }^{[21-23]}$

Second, the objective of Naude et al.'s ${ }^{[2]}$ article was 'To compare the effects of low (sic) $\mathrm{CHO}$ and isoenergetic balanced weight loss diets in overweight and obese adults. As a key effect of the low$\mathrm{CHO}$ diet is to reduce hunger by increasing satiety despite a reduced energy intake, ${ }^{[24]}$ the caloric intake of subjects on the control diet in isoenergetic trials must be voluntarily restricted to match this effect. This effectively negates the advantage provided by the uniquely satiating effect of genuinely low-CHO diets.

Both of these points served to disadvantage the lower-CHO diets included by Naude et al. ${ }^{[2]}$ in their systematic review.

Regarding the first point, the introduction to the Naude et al. ${ }^{[2]}$ article confirmed the authors' understanding of what constitutes a low-CHO diet: 'Some weight loss diets widely promoted through the media ... recommend a regime greatly restricting carbohydrates $(\mathrm{CHO})$.' The introduction continued: 'To achieve the very low $\mathrm{CHO}$ intake, these diets prescribe restriction of most vegetables and fruit ... ? Confirming their understanding of what constitutes a low$\mathrm{CHO}$ diet, the authors proceeded to find against these diets without actually studying them. Only 1 of the 19 trials they initially reviewed was sufficiently low in $\mathrm{CHO}$ to qualify as a trial of the (therapeutic) low-CHO diet. ${ }^{[13]}$ The other 18 trials reviewed were lower in $\mathrm{CHO}$ content than current public health dietary guidelines, but they were not low-CHO diets. There is a substantial difference between lower(than dietary guidelines) and therapeutically low-CHO diets. The therapeutic low-CHO diet is prescribed specifically to lower the daily $\mathrm{CHO}$ intake to $<50 \mathrm{~g} /$ day, which is the level at which optimal benefits of this dietary intervention occur. ${ }^{[2]}$

In view of the pivotal importance of this article to the conduct of the 'trial' against low-CHO diets in SA, we considered it important to submit the article to a rigorous re-analysis. In the course of our investigation we uncovered a multitude of errors that materially altered the conclusions promoted by the article.

In the context of the current debate on low-CHO diets in $\mathrm{SA}$, it is important that the erroneous messages conveyed to the SA public as a result of the inaccuracies in that study ${ }^{[2]}$ should be rectified expeditiously.

\section{A re-examination of the Naude et al. ${ }^{[2]}$ article}

The main conclusion

The main conclusion presented in the abstract of the Naude et al. ${ }^{[2]}$ article was: 'In non-diabetic participants, our analysis showed little or no difference in mean weight loss in the two groups at $3-6$ months.' This conclusion was based on a study of 14 trials that were deemed moderate-quality evidence. ${ }^{[7-20]}$

\section{The studies selected}

The inclusion criteria set for the selection of these 14 studies by Naude et al. ${ }^{[2]}$ were: randomised controlled trials (RCTs); published in English; >10 participants randomised in each group; diet was the only intervention; control and intervention diets were isocaloric (isoenergetic); complete macronutrient profile of intervention diet 
was available; control diet was deemed balanced (defined as 45 - 65\%, $25-35 \%$ and $10-20 \%$ of total energy from $\mathrm{CHO}$, fat and protein, respectively); and the follow-up period was $\geq 12$ weeks.

We started with the assumption that the 14 studies had been chosen in good faith. It transpired that the following four studies should not have been included:

- Luscombe et al. ${ }^{[16]}$ as it was a duplication of Farnsworth et al.' ${ }^{15]}$ article. - Keogh et al. ${ }^{[17]}$ and Sacks et al., ${ }^{[14]}$ as they failed the inclusion criteria set by Naude et al. ${ }^{[2]}$ that fat should provide $25-35 \%$ of the energy in a balanced diet. Instead, fat provided only $20 \%$ of the target calories in the control diets in both those studies.

- De Luis et al. ${ }^{[9]}$ as the data are not conducive to meta-analysis. The two De Luis et al..$^{[8,9]}$ studies are visibly incongruent in Fig. 3 of the Naude et al. ${ }^{[6]}$ article (Supplemental material 1: Table $4^{\star}$ ). Fig. 3 reported weight data from the end of the trial (but without data on weight at the start of the trial), when weight loss during the trial was the target outcome. The error of including these data is inexplicable. The study of De Luis et al. ${ }^{[9]}$ cannot be used in meta-analysis, as the study did not report standard deviation (SD) data for the weight losses in the diet and control groups. However, the data of De Luis et al. ${ }^{[8]}$ can be used in meta-analysis. We extracted the weight loss and SD data from De Luis et al. ${ }^{[8]}$ as Naude et al. ${ }^{[2]}$ should have done for consistency with their other methods of data extraction (Supplemental material 1: Table $6^{*}$ ).

\section{The meta-analysis sub-grouping}

Naude et al. ${ }^{[6]}$ split the 14 studies into so-called 'high fat variants' and 'high protein variants'. Neither achieved a significant result. However, this split was not justified. Sub-grouping may be undertaken in meta-analysis when two different interventions are being compared, e.g. the comparison of the effects of two different drugs v. no drug control. The sub-grouping of studies into those deemed 'high fat' or 'high protein' was not justified, as Naude et al.' ${ }^{\text {'[2] }}$ original objective was not to compare high-fat or high-protein diets with balanced diets. Their objective was ostensibly to study the effects of 'low'-CHO diets by comparing lower-CHO diets v. balanced diets.

Furthermore, the classification of diets as either high fat or high protein by Naude et al. ${ }^{[2]}$ was entirely subjective. To clarify, the studies of Frisch et al. ${ }^{[10]}$ and Klemsdal et al. ${ }^{[1]]}$ complicated calculations of the average macronutrient compositions of all the diets, as these authors reported only the ranges of macronutrient intakes. Frisch et al. ${ }^{[10]}$ reported $\mathrm{CHO} /$ fat/protein percentage proportions as $<40 />35 / 25$ and $>55 /<30 / 15$ for the diet and control groups, respectively. Klemsdal et al. ${ }^{[11]}$ reported $\mathrm{CHO} /$ fat/protein percentage proportions as $30-35 / 35-40 / 25-30$ and $55-60 /<30 / 15$ for diet and control groups, respectively.

We used $\mathrm{CHO} /$ fat/protein in percentage proportions of 40/35/25 and 55/30/15 for the diet and control groups, respectively, in the study by Frisch et al., ${ }^{[10]}$ and 33/38/28 (mid-points rounded up) and $55 / 30 / 15$ for the respective groups in the study of Klemsdal et al., ${ }^{[11]}$ to calculate average macronutrient intakes for the 14 studies included in the Naude et al. ${ }^{[2]}$ meta-analysis as 35/35/30 for the diet groups and $56 / 27 / 17$ for the control groups. Protein intake in the diet groups of their so-called low-CHO high-protein (LCHP) and low-CHO highfat (LCHF) studies averaged $31.5-32.5 \%$ and $28.4 \%$, respectively, probably a biologically insignificant difference. (The variation in the protein proportion for the LCHP group results from macronutrient proportions differing in the abstract and narrative of two studies ${ }^{[15-16]}$ (Supplemental material 1: Table $2^{*}$ )). In the studies by Lim et al. ${ }^{[13]}$ and Aude et al. ${ }^{[7]}$ there were higher percentage protein intakes than in four of the six studies placed in their high-protein group. ${ }^{[15,16,18,19]}$ Additionally, if the four studies were excluded that should have been excluded, ${ }^{[9,14,16,17]}$ the protein differential narrows even further to $31.3 \%$ and $29.3 \%$ for so-called LCHP and LCHF, respectively. The sub-grouping was therefore not necessary, not justified and not robust.

\section{Errors in data extraction}

The primary claim emanating from the Naude et al. ${ }^{[2]}$ article was that there was little or no difference in mean weight loss between a lower-CHO diet and a so-called balanced diet. This was the only part of the article that we re-examined. We found tens of errors in this re-examination. These are fully detailed in the Supplemental material 1: Tables $1-6 .^{\star}$ The material errors that we detected are summarised as follows:

- The findings in the studies by Frisch et al. ${ }^{[10]}$ Layman et al. ${ }^{[19]}$ Lim et al. ${ }^{[13]}$ and Wycherley et al. ${ }^{[20]}$ all favoured the lower-CHO intervention. For all of these studies, Naude et al. ${ }^{[2]}$ reported the number of completers in the study at a time later than that at which the weight loss data they included had been recorded. This resulted in lower weighting being assigned to these studies in meta-analysis, as these studies would appear to include fewer participants than was the case. This would have disadvantaged the overall pooled effect for lower-CHO diets.

- The study of Wycherley et al. ${ }^{[20]}$ included weight loss data for 52 weeks of the trial. Naude et al. ${ }^{[2]}$ reported that they had used those data, but they did not. Instead, they used data from 12 weeks of the study. Use of the 52-week data would have favoured the lower-CHO intervention.

- Krauss et al. ${ }^{[12]}$ illustrated the macronutrient compositions of four different diets. Three diets differed in macronutrient composition, but not in saturated fatty acids (SFAs) and were marked as planned (a priori) comparisons. The $\mathrm{CHO}$ content of these three were 54\%, $39 \%$ and $26 \%$, respectively. The fourth diet also contained $26 \%$ $\mathrm{CHO}$, but was reported as high in SFA and marked as intended to be compared with the $26 \% \mathrm{CHO} / \mathrm{low}$-SFA diet alone. Naude et al. ${ }^{[2]}$ compared the $26 \%$ high-SFA diet with the balanced low-SFA diet, which unnecessarily introduced a second variable and was to the disadvantage of the direct comparison between the lower- $\mathrm{CHO}$ and the balanced diet.

- The studies by Farnsworth et al. ${ }^{[15]}$ and Luscombe et al. ${ }^{[16]}$ were a duplication of the same study. Both studies favoured the control balanced dietary intervention. Furthermore, the weight loss in the control diet intervention was reported by Naude et al. ${ }^{[2]}$ as $7.95 \mathrm{~kg}$, rather than the $7.9 \mathrm{~kg}$ actually reported by Farnsworth et al. ${ }^{[15]}$

- The use of end-value data for body weight, not weight loss, in the De Luis et al. ${ }^{[8,9]}$ studies was absurd and favoured the control balanced dietary intervention.

- The weight loss data for the study by Krauss et al. ${ }^{[12]}$ as reported by Naude et al. ${ }^{[2]}$ recorded equal weight losses for the diet and control groups. Those specific data could not be found in the original publication. Instead, the actual data reported by Krauss et al. ${ }^{[12]}$ slightly favoured the lower-CHO diet intervention.

- The study by Sacks et al. ${ }^{[14]}$ should not have been included, as it did not meet Naude et al.' $\mathrm{s}^{[2]}$ criteria for inclusion. Having been included, the data for weight loss appear to have been reported the wrong way round so that the slightly higher weight loss occurring in the lower-CHO diet was incorrectly assigned to the control diet.

- The study by Keogh et al. ${ }^{[17]}$ similarly failed Naude et al.' ${ }^{[2]}$ inclusion criteria, but the data for weight loss in that study slightly favoured the lower-CHO diet intervention. However, the data for the number of completers were taken at the end of the study, whereas the data for weight loss were from an earlier part of the trial. This mitigated some of any advantage afforded to the lower-CHO diet intervention.

All errors made, except for part of the last one listed, ${ }^{[17]}$ favoured the control group. 


\section{Study limitations}

A number of the studies were not designed to evaluate weight loss as their primary objective. The study of De Luis et al. ${ }^{[9]}$ was designed to study two different hypocaloric diets on the secretion of glucagon-like peptide 1 . Another study by De Luis et al ${ }^{[8]}$ evaluated weight loss and blood adipocytokine concentrations in obese subjects with a genetic variant. Keogh et al. ${ }^{[17]}$ studied flow-mediated dilatation, adhesion molecules and adiponectin after weight loss. The primary aim of the Klemsdal et al. ${ }^{[11]}$ study was to evaluate the impact of low glycaemic load v. low-fat diets in people with and without the metabolic syndrome. Krauss et al. ${ }^{[12]}$ sought to study the effects of reduced $\mathrm{CHO}$ intake and weight loss on atherogenic dyslipidaemia. Lasker et al. ${ }^{[18]}$ studied the metabolic effects of two different weight loss diets on dyslipidaemia and post-prandial insulin responses to a meal.

A number of the studies lacked generalisability to whole populations. Wycherley et al. ${ }^{[20]}$ and Krauss et al. ${ }^{[12]}$ studied males only. Farnsworth et al. ${ }^{[15]}$ and Luscombe et al. ${ }^{[16]}$ (noting that these are duplicate studies) studied men and women with insulin resistance and hyperinsulinaemia. De Luis et al. ${ }^{[8]}$ included only obese subjects with the rs9939609 genetic variant.

A number of the authors did not consider their interventions to be low-CHO diets. Lasker et al. ${ }^{[18]}$ and Layman et al. ${ }^{[19]}$ described their interventions as moderate-protein diets. The diet in Lasker et al.' ${ }^{[18]}$ study was additionally reported as 'moderate carbohydrate', whereas Farnsworth et al. ${ }^{[15]}$ and Luscombe et al. ${ }^{[16]}$ (duplicate studies) considered their interventions to be high-protein diets. The studies by De Luis et al ${ }^{[8,9]}$ were described as hypocaloric. Frisch et al. ${ }^{[10]}$ reported that their study contrasted the effects of CHO-reducedintake and fat-reduced-intake diets. Wycherley et al. ${ }^{[20]}$ considered their study to be a 52-week comparison of either high-protein or high-CHO diets.

In addition, the four studies ${ }^{[25-28]}$ reviewed by Naude et al. ${ }^{[2]}$ to compare lower-CHO diets with balanced diets in overweight and obese adults with type 2 diabetes were of concern. We ask ourselves how interventions recommending a $40 \% \mathrm{CHO}$ intake to participants who cannot metabolise carbohydrate effectively because they have diabetes mellitus type 2 were granted ethical approval.

\section{A revised meta-analysis}

Notwithstanding that the Naude et al. ${ }^{[2]}$ article: (i) did not review genuinely low-CHO diets; and (ii) introduced an isocaloric inclusion criterion, which negated the natural advantage of low- $\mathrm{CHO}$ diets, to be robust in our re-examination we re-conducted the meta-analysis without the errors made by Naude et al..$^{[2]}$

The meta-analysis was repeated for the 10 studies that could be included in this analysis according to the authors' own selection criteria (Supplemental material 2: Meta-analysis, Fig. $1^{\star}$ ). Heterogeneity was evaluated using the Q-value, $\mathrm{I}^{2}$ and $\mathrm{T}^{2}$ calculations. Analyses were performed using Comprehensive Meta-Analysis version 2 (Biostat, USA). The overall pooled effect was calculated using random effects meta-analysis. The standard difference in means was significant at -0.272 ( $95 \%$ confidence interval $-0.506,-0.039$ ).

In conclusion, when meta-analysis was performed on the 10 studies that qualified for inclusion in the study of Naude et al. ${ }^{[2]}$ using their own criteria, the data confirmed that the lower- $\mathrm{CHO}$ diet produced significantly greater weight loss than did the balanced diet.

\section{Discussion}

The findings of the Naude et al. ${ }^{[2]}$ meta-analysis were widely reported in the SA media as disproof of the overall value of the LCHF diet. Indeed, some reports misused this messaging to warn about the 'dangerous' nature of low-CHO diets.
The objective of our re-examination was to test whether or not the findings of the Naude et al. ${ }^{[2]}$ article were robust. We have demonstrated that they were not. The main limitation of our article is that we re-examined only one part of Naude et al.' $\mathrm{s}^{[2]}$ article. We found their analysis of the weight loss data to have many errors and those errors to have made a material difference to the conclusions. Given the number of errors we detected in that single section of the article, it is inconceivable that the remainder of the article is robust. Therefore, without the need to examine all sections of the article, we have shown that in its published form, it is not robust and cannot be relied on.

We additionally showed that, notwithstanding two features of the study, which by design or by chance disadvantaged low-CHO diets, had the Naude et al. ${ }^{[2]}$ meta-analysis been properly performed, it would have concluded that the lower-CHO diet produced greater weight loss than the balanced diet. This would have radically altered the nature of the message heard across SA after its publication and might have influenced the eagerness of SA medical authorities to put the LCHF/Banting diet on public 'trial'.

A reasonable question to ask is: how could the published metaanalysis have included so many errors and have come to the incorrect conclusion despite peer review? Another reasonable question to ask is: what is the chance that essentially all these errors favoured the so-called balanced diet and disadvantaged the lower-CHO diet, especially when many of the authors of this article are on public record as being vigorously opposed to lower- or low-CHO diets and to those who promote such eating plans?

${ }^{*}$ Supplemental material. Supplemental material 1: Tables 1 - 6, and Supplemental material 2: Meta-analysis, are available from the corresponding author on request.

Declarations of interest. $\mathrm{ZH}$ receives income from writing and from two small self-employment businesses: The Harcombe Diet Co. and Columbus Publishing. TN is the author of the books Lore of Running and Waterlogged and co-author of The Real Meal Revolution, Raising Superheroes and Challenging Beliefs. All royalties from the sales of The Real Meal Revolution and Raising Superheroes and related activities are donated to the Noakes Foundation, of which he is the chairman and which funds research on insulin resistance, diabetes and nutrition as directed by its Board of Directors. Money from the sale of other books is donated to the Tim and Marilyn Noakes Sports Science Research Trust, which funds the salary of a senior researcher at the University of Cape Town, South Africa. The research focuses on the study of skeletal muscle in African mammals, with some overlap to the study of type 2 diabetes in carnivorous mammals and of the effects of (scavenged) sugar consumption on freeliving (wild) baboons.

1. Houliston T. Low-carb diets not better than balanced eating! Womens Health, 10 July 2014.

2. Naude CE, Schoonees A, Senekal M, Young T, Garner P, Volmink J. Low carbohydrate versus isoenergetic balanced diets for reducing weight and cardiovascular risk: A systematic review and metaanalysis. PLoS ONE 2014;9(7):e100652. http://dx.doi.org/10.1371/journal.pone.0100652

3. Stassen W. New research could debunk banting diet. South African Health News Service, 10 July 2014 4. Stassen W. Noakes's low-carb diet not healthier. Cape Times, 10 July 2014.

5. Ismail A. Tim Noakes to face inquiry over 'Banting' tweet. Health24, 20 October 2015.

6. Naude CE, Schoonees A, Senekal M, Young T, Garner P, Volmink J. Low carbohydrate versu isoenergetic balanced diets for reducing weight and cardiovascular risk: A systematic review and metaanalysis. PLoS ONE 2014;9(7):18 (Fig. 3)e100652. http://dx.doi.org/10.1371/journal.pone.0100652

7. Aude YW, Agatston AS, Lopez-Jimenez F, et al. The national cholesterol education program diet vs a diet lower in carbohydrates and higher in protein and monounsaturated fat: A randomized trial. Arch Intern Med 2004;164(19):2141-2146. http://dx.doi.org/10.1001/archinte.164.19.2141

8. De Luis DA, Aller R, Izaola O, et al. Evaluation of weight loss and adipocytokines levels after two hypocaloric diets with different macronutrient distribution in obese subjects with rs9939609 gene variant. Diabetes Metab Res Rev 2012;28(8):663-668. http://dx.doi.org/10.1002/dmrr.2323

9. De Luis DA, Sagrado MG, Conde R, Aller R, Izaola O. The effects of two different hypocaloric diets on glucagon-like peptide 1 in obese adults, relation with insulin response after weight loss. J Diabetes Complications 2009;23(4):239-243. http:///dx.doi.org/10.1016/j.jdiacomp.2007.12.006

10. Frisch S, Zittermann A, Berthold HK, et al. A randomized controlled trial on the efficacy of carbohydrate-reduced or fat-reduced diets in patients attending a telemedically guided weight loss program. Cardiovasc Diabetol 2009;8:36. http://dx.doi.org/10.1186/1475-2840-8-36 
11. Klemsdal TO, Holme I, Nerland H, Pedersen TR, Tonstad S. Effects of a low glycemic load diet versus a low-fat diet in subjects with and without the metabolic syndrome. Nutr Metab Cardiovasc Dis 2010;20(3):195-201. http://dx.doi.org/10.1016/j.numecd.2009.03.010

12. Krauss RM, Blanche PJ, Rawlings RS, Fernstrom HS, Williams PT. Separate effects of reduced carbohydrate intake and weight loss on atherogenic dyslipidemia. Am J Clin Nutr 2006;83(5):1025-1031; quiz 205.

13. Lim SS, Noakes M, Keogh JB, Clifton PM. Long-term effects of a low carbohydrate, low fat or high unsaturated fat diet compared to a no-intervention control. Nutr Metab Cardiovasc Dis 2010;20(8):599unsaturated fat diet compared to a no-intervention cont
607. http://dx.doi.org/10.1016/j.numecd.2009.05.003

14. Sacks FM, Bray GA, Carey VJ, et al. Comparison of weight-loss diets with different compositions of fat, 4. Sacks FM, Bray GA, Carey VJ, et al. Comparison of weight-loss diets with different compositions of fat,
protein, and carbohydrates. N Engl J Med 2009;360(9):859-873. http://dx.doi.org/10.1056/NEJMoa0804748

15. Farnsworth E, Luscombe ND, Noakes M, Wittert G, Argyiou E, Clifton PM. Effect of a high-protein Farnsworth E, Luscombe ND, Noakes M, Wittert G, Argyiou E, Clifton PM. Effect of a high-protein,
energy-restricted diet on body composition, glycemic control, and lipid concentrations in overweight

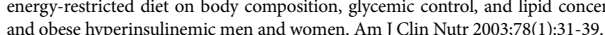

16. Luscombe ND, Clifton PM, Noakes M, Farnsworth E, Wittert G. Effect of a high-protein, energyrestricted diet on weight loss and energy expenditure after weight stabilization in hyperinsulinemi subjects. Int J Obes Relat Metab Disord 2003;27(5):582-590. http://dx.doi.org/10.1038/sj.ijo.0802270

17. Keogh JB, Brinkworth GD, Clifton PM. Effects of weight loss on a low-carbohydrate diet on flowmediated dilatation, adhesion molecules and adiponectin. Br J Nutr 2007;98(4):852-859. http://dx.doi org $10.1017 / 50007145077478$

18. Lasker DAW, Evans EM, Layman DK. Moderate carbohydrate, moderate protein weight loss diet reduces cardiovascular disease risk compared to high carbohydrate, low protein diet in obese adults: $A$ randomized clinical trial. Nutr Metab 2008,5.30. hitp:// $\mathrm{dx}$.doi.org/10.1186/1743-7075-5-30

9. Layman DK, Evans EM, Erickson D, et al. A moderate-protein diet produces sustained weight loss and long-term changes in body composition and blood lipids in obese adults. J Nutr 2009;139(3):514-521. http://dx.doi.org/10.3945/jn.108.09944

20. Wycherley TP, Brinkworth GD, Clifton PM, Noakes M. Comparison of the effects of 52 weeks weight loss with either a high-protein or high-carbohydrate diet on body composition and cardiometabolic ris factors in overweight and obese males. Nutr Diabetes 2012;2:e40. http://dx.doi.org/10.1038/nutd.2012.11
21. Dashti HM, Mathew TC, Hussein T, et al. Long-term effects of a ketogenic diet in obese patients. Exp Clin Cardiol 2004;9(3):200-205.

22. Feinman RD, Pogozelski WK, Astrup A, et al. Dietary carbohydrate restriction as the first approach in diabetes management. Critical review and evidence base. Nutrition 2014. http://dx.doi.org/10.1016/j.
dition nut.2014.06.011

23. Paoli A, Rubini A, Volek JS, Grimaldi KA. Beyond weight loss: A review of the therapeutic uses of verylow-carbohydrate (ketogenic) diets. Eur J Clin Nutr 2013;67(8):789-796. http://dx.doi.org/10.1038/ ejcn.2013.116

24. Yudkin J, Carey M. The treatment of obesity by the 'highfat' diet. The inevitability of calories. Lancet 1960;2(7157):939-941.

25. Brinkworth GD, Noakes M, Parker B, Foster P, Clifton PM. Long-term effects of advice to consume a high-protein, low-fat diet, rather than a conventional weight-loss diet, in obese adults with type 2 diabetes: One-year follow-up of a randomised trial. Diabetologia 2004;47(10):1677-1686. http://dx.doi. $\mathrm{rg} / 10.1007 / \mathrm{s} 00125-004-1511-7$

26. Krebs JD, Elley CR, Parry-Strong A, et al. The Diabetes Excess Weight Loss (DEWL) trial: A randomised controlled trial of high-protein versus high-carbohydrate diets over 2 years in type 2 diabetes. Diabetologia 2012;55(4):905-914. http://dx.doi.org/10.1007/s00125-012-2461-0

27. Larsen RN, Mann NJ, Maclean E, Shaw JE. The effect of high-protein, low-carbohydrate diets in the reatment of type 2 diabetes: A 12 month randomised controlled trial. Diabetologia 2011;54(4):731740. http://dx.doi.org/10.1007/s00125-010-2027-y

28. Parker B, Noakes M, Luscombe N, Clifton P. Effect of a high-protein, high-monounsaturated fat weight loss diet on glycemic control and lipid levels in type 2 diabetes. Diabetes Care 2002;25(3):425-430.

Accepted 29 September 2016 